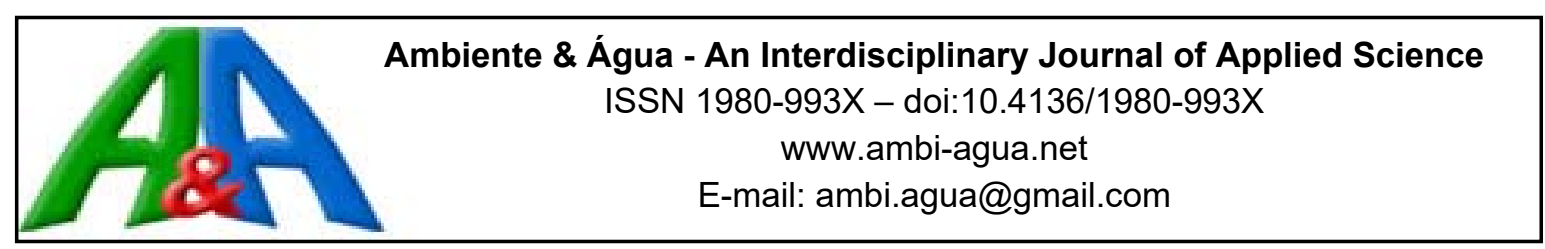

\title{
Caracterização estacional das variáveis físicas, químicas, biológicas e ecotoxicológicas em um trecho do Rio Paraíba do Sul, SP, Brasil
}

\author{
doi:10.4136/ambi-agua.1949 \\ Received: 30 May 2016; Accepted: 23 Jan. 2017 \\ Lucas Gonçalves Queiroz*; Flávio Teixeira da Silva; \\ Teresa Cristina Brazil de Paiva
Universidade de São Paulo (USP), Escola de Engenharia de Lorena (EEL), Lorena, SP, Brasil
Departamento de Bioquímica
*Autor correspondente: e-mail: lucasgoncalvesqueiroz@gmail.com, flavio@debiq.eel.usp.br, teresa@debiq.eel.usp.br

\section{RESUMO}

O Rio Paraíba do Sul está localizado em uma região brasileira com elevada densidade populacional e grande importância socioeconômica. Em seu trecho paulista, o rio encontra-se impactado e com a qualidade da água comprometida devido à retirada da vegetação ciliar, o aumento de áreas impermeáveis, a atividade industrial, a utilização de insumos agrícolas e, principalmente, pelo lançamento de esgotos sem tratamento adequado. O objetivo deste trabalho foi caracterizar, durante as estações seca e chuvosa, a qualidade da água do Rio Paraíba do Sul quanto as variáveis físicas, químicas, biológicas e ecotoxicológicas em seu trecho médio superior. As coletas das amostras foram realizadas trimestralmente entre os meses de agosto de 2013 e agosto de 2014. Foram determinadas variáveis: $\mathrm{pH}$, temperatura, condutividade, turbidez, oxigênio dissolvido (OD), demanda bioquímica de oxigênio (DBO), demanda química de oxigênio (DQO), fósforo total (PT), sólidos totais (ST), coliformes termotolerantes (CT), clorofila-a, efeito tóxico agudo (ETA) e crônico (ETC) e Índice de Estado Trófico (IET). Os resultados referentes à qualidade das águas mostraram que as variáveis $\mathrm{OD}, \mathrm{PT}$ e CT estavam em desacordo com o estabelecido para um rio classe 2, conforme a resolução CONAMA 357/2005 (2005). Algumas variáveis apresentaram uma redução ao longo do período avaliado, como DBO $(42,4 \%)$, ST $(31,1 \%)$ e DQO $(21,3 \%)$. No período chuvoso foram observados ETA e ETC. A análise estatística mostrou que a precipitação pluviométrica possui grande influência sobre OD, DBO, ST, clorofila- $a$, ETA e ETC, atuando como um possível agente intensificador de impactos sobre este manancial.

Palavras-chave: contaminação da água, ecotoxicologia aquática, organismos-teste, precipitação pluviométrica, uso do solo.

\section{Seasonal characterization of the physical, chemical, biological and ecotoxicological variables in a stretch of the Paraíba do Sul River, SP, Brazil}

\section{ABSTRACT}

The Paraíba do Sul River is located in a Brazilian region with high population density and great socio-economic importance. In the São Paulo stretch, the river is impacted and water 
quality is impaired due to the removal of riparian vegetation, increases in impermeable surfaces, industrial activity, the use of agricultural inputs, and the release of wastewater without proper treatment. This study characterized the physical, chemical, biological and ecotoxicological variables associated with the water quality of the Paraíba do Sul River in the upper-middle stretch during the dry and wet seasons. The sampling was carried out quarterly between August 2013 and August 2014. The variables evaluated were $\mathrm{pH}$, temperature, conductivity, turbidity, dissolved oxygen (OD), biochemical oxygen demand (DBO), chemical oxygen demand (DQO), total phosphorus (PT), total solids (ST), fecal coliforms (CT), chlorophyll-a, acute toxic effect (ETA) and chronic toxic effect (ETC) and Trophic State Index (IET). The results showed that the variables OD, PT and CT were not in accordance with those established for a Class 2 aquatic environment, according to the National Counsel for the Environment 357/2005 (Portuguese acronym "CONAMA"). Some variables showed a reduction during the evaluated period, such as DBO (42.4\%), ST (31.1\%) and DQO (21.3\%). Both ETA and ETC were observed in the rainy period. The statistical analysis showed that the rainfall has an influence on OD, DBO, ST, chlorophyll- $a$, ETA and ETC, acting as a possible intensifier agent of impacts on the river.

Keywords: aquatic ecotoxicology, land use, pluviometric precipitation, test organisms, water contamination.

\section{INTRODUÇÃO}

A Bacia do Rio Paraíba do Sul, localizada no sudeste brasileiro entre os estados de São Paulo, Minas Gerais e Rio de Janeiro, constitui um importante eixo de desenvolvimento socioeconômico no país, devido à elevada densidade populacional, grau de urbanização e industrialização (Demanboro, 2015).

O grande desenvolvimento da região, entretanto, é motivo de problemas em relação à disponibilidade de água. Apesar de apresentar uma das maiores demandas hídricas do país, a região possui uma das menores disponibilidades relativas (ANA, 2012).

Áreas urbanizadas e agrícolas possuem grande potencial de degradação de corpos hídricos, sobretudo quando há um baixo grau de saneamento e mitigação de agentes causadores de impacto ambiental. Atividades nestas áreas alteram a qualidade da água, pela adição de nutrientes, matéria orgânica e contaminantes (Carvalho et al., 2015, Passig et al., 2015).

Ao longo dos anos, o Rio Paraíba do Sul tem sido constantemente impactado devido ao intenso uso e ocupação do solo, resultando na retirada da vegetação e aumento de áreas impermeáveis, utilização de insumos agrícolas e, principalmente, pelo lançamento de efluentes domésticos e industriais sem tratamento adequado. Estes impactos promovem a redução da qualidade da água deste manancial afetando diretamente a disponibilidade hídrica, as comunidades aquáticas e o abastecimento público (Malafaia et al., 2012; CEIVAP, 2014).

O objetivo deste estudo foi avaliar os efeitos da precipitação e correlacioná-los às variáveis associadas à qualidade da água do Rio Paraíba do Sul, em seu trecho paulista, frente aos impactos causados pelas atividades humanas. Esta região possui grande importância socioeconômica devido à elevada densidade populacional, presença de indústrias e áreas destinadas à agricultura. Estas condições resultam na perda da qualidade da água, devido a elevada demanda hídrica, lançamento de poluentes e retirada da cobertura vegetal. Deste modo, um maior conhecimento acerca deste corpo hídrico pode auxiliar na promoção de formas de gestão para preservação e consequente melhoria da qualidade da água. 


\section{METODOLOGIA}

\section{1. Área de estudo}

O Rio Paraíba do Sul (RPS) nasce pela confluência dos rios Paraibuna e Paraitinga, no Estado de São Paulo, percorre cerca de $1.150 \mathrm{Km}$ e deságua no município de São João da Barra, no Estado do Rio de Janeiro (CEIVAP, 2014, Marengo e Alves, 2005). Esta região apresenta elevada densidade populacional, presença de indústrias e áreas cultiváveis.

O trecho avaliado está localizado entre os municípios de Aparecida e Cachoeira Paulista, onde suas águas são destinadas principalmente ao abastecimento, diluição de esgotos, irrigação e geração de energia, sendo classificado como Classe 2. A Figura 1 apresenta os diferentes usos do solo do trecho, os quais refletem diretamente na qualidade da água.

A partir das imagens de satélite Landsat TM-5 (Figura 1), foi possível calcular a frequência relativa das classes de cobertura do solo da região. Em seu trecho paulista, as áreas urbanizadas correspondem a 9,3\% da bacia e as áreas agrícolas e de pastagens correspondem juntas a 36,9\%. Estas atividades estão localizadas principalmente próximas às margens do RPS, causando impactos sobre o corpo hídrico e em suas áreas adjacentes.

\subsection{Coleta de amostras}

Foram realizadas cinco coletas de água em oito pontos próximos à montante $(\mathrm{M}) \mathrm{e}$ à jusante (J) do perímetro urbano de quatro municípios paulistas: Aparecida (APDM (-22.858095, 45.254591) e APDj (-22.842567, -45.234106)), Guaratinguetá (GUAm (-22.811946, 45.194412) e GUAJ (-22.790639, -45.178652)), Lorena (LORM (-22.742899, -45.144604) e LORJ (-22.698778, -45.115863)) e Cachoeira Paulista (CPTM (-22.634923, -44.991708) e CPTJ (-22.664032, -45.023458)). A localização dos pontos permite observar a contribuição de cada município avaliado sobre a poluição do RPS. As coletas foram realizadas trimestralmente entre os meses de agosto de 2013 e agosto de 2014 e preservadas conforme critérios determinados pela norma ABNT NBR 9.898/87 (ABNT, 1987). Os dados pluviométricos foram fornecidos pelo Departamento de Águas e Energia Elétrica (DAEE) dos municípios de Lorena e Guaratinguetá e utilizados para caracterizar os períodos de precipitação na região (Figura 2).

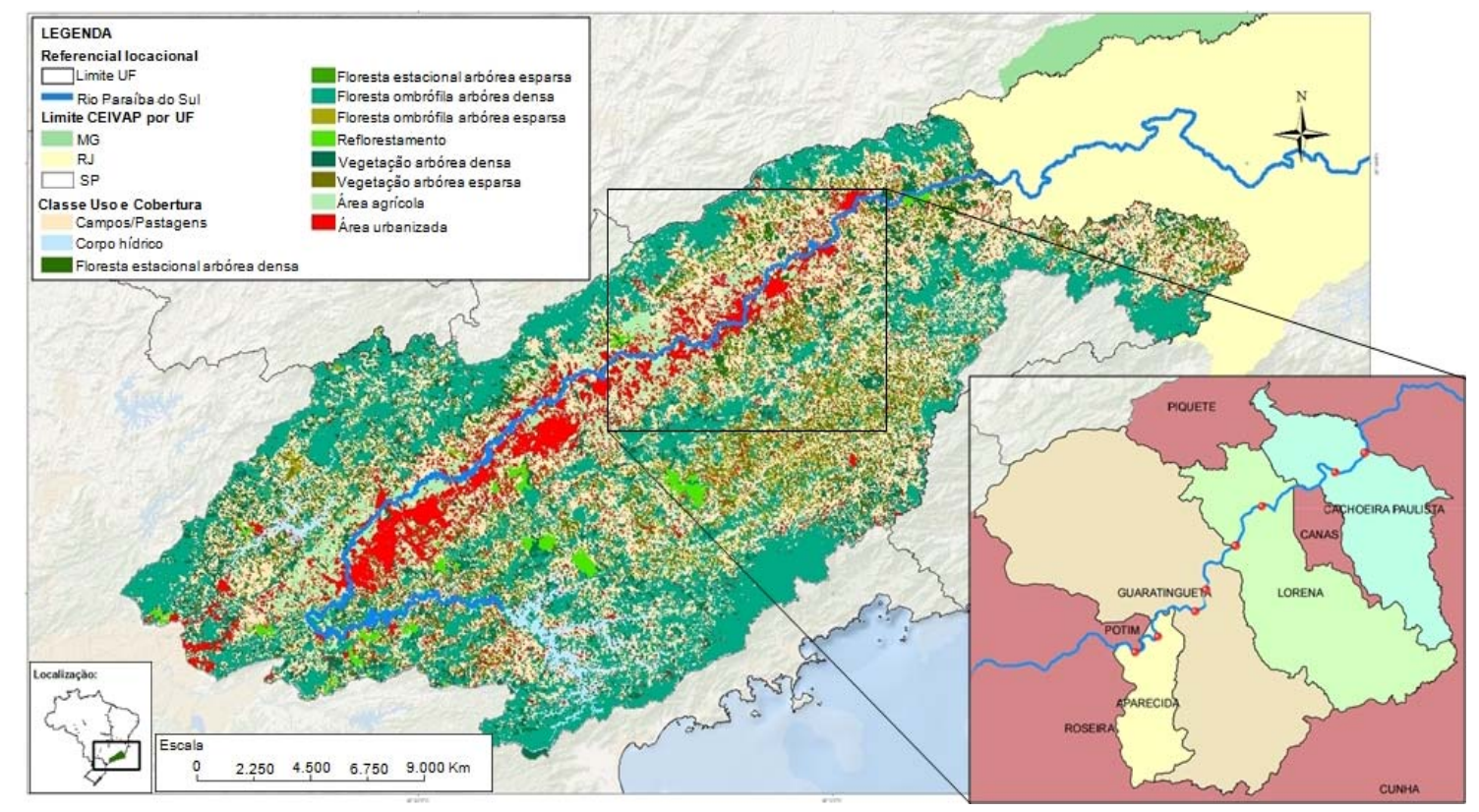

Figura 1. Uso e ocupação do solo no trecho paulista da Bacia do Rio Paraíba do Sul (com base na classificação de imagens Landsat TM 5). 


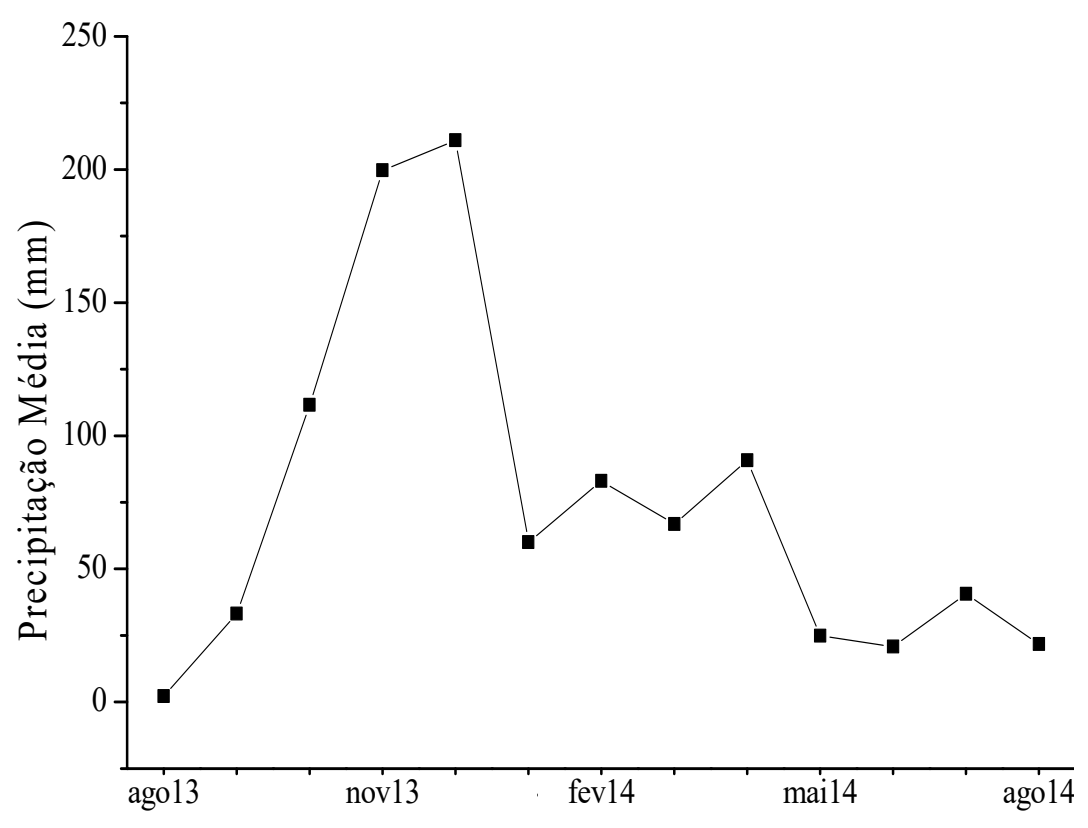

Figura 2. Média mensal dos valores de precipitação $(\mathrm{mm})$ observados entre agosto de 2013 e agosto de 2014.

Fonte: DAEE (2014)

\subsection{Análises físicas, químicas, biológicas e ecotoxicológicas}

No momento da coleta, foram determinadas as variáveis $\mathrm{pH}$, a condutividade e a temperatura com auxílio de uma sonda multiparamétrica (HANNA modelo HI9811-5). Os valores de oxigênio dissolvido (OD), demanda bioquímica de oxigênio (DBO), demanda química de oxigênio (DQO) e a concentração de fósforo total (PT) foram determinadas de acordo com APHA ET AL. (2015). A turbidez foi determinada a partir de turbidímetro (TB 1000 ), os sólidos totais (ST) pelo método gravimétrico e o nitrogênio total (NT) pelo método Kjeldahl adaptado (Galvani e Gaertner, 2006).

A quantificação de coliformes termotolerantes (CT) foi realizada segundo APHA ET AL. (2015), e para a concentração de clorofila- $a$ utilizou-se o método proposto por Lorezen (1967).

Bioensaios para determinação de efeito tóxico agudo (ETA) com Daphnia similis e efeito tóxico crônico (ETC) com Raphidocelis subcapitata foram realizados conforme as normas ABNT NBR 12.713/16 e NBR 12.648/11 (ABNT, 2011; 2016), respectivamente.

\subsection{Análises estatísticas}

Com o intuito de avaliar como as variáveis físicas, químicas, biológicas e ecotoxicológicas estão correlacionadas entre si, foi aplicada a Correlação de Spearman, utilizando o software Statistica versão 7.0 (2008), bem como a Análise dos Componentes Principais (ACP) com uso do software Past versão 2.16 (2001), a fim de identificar as variáveis mais relevantes em cada um dos períodos avaliados.

\section{RESULTADOS E DISCUSSÃO}

\subsection{Características físicas, químicas e biológicas}

A Tabela 1 apresenta os valores obtidos a partir da determinação das variáveis físicas, químicas e biológicas em amostras de água coletadas num trecho do RPS durante 1 ano (2013-2014). Os valores em destaque apresentam os resultados em desconformidade com a resolução CONAMA 357/05 para um corpo hídrico classe 2. 
A maioria das amostras de água (92,5\%) apresentou valores de $\mathrm{pH}$ dentro do estabelecido pelo CONAMA 357/05, porém observou-se que todos os valores de $\mathrm{pH}$ estiveram muito próximos de limite inferior. A condutividade, por sua vez, variou de 80 a $240 \mu \mathrm{S} \mathrm{cm}^{-1}$ em que a maioria dos valores obtidos foi igual ou inferior a $100 \mu \mathrm{S} \mathrm{cm}^{-1}$. De acordo com CETESB (2009), os valores acima de $100 \mu \mathrm{S} \mathrm{cm}^{-1}$ podem ser interpretados como decorrentes de concentrações elevadas de poluentes, visto que estes possuem muitos íons dissolvidos. A turbidez apresentou os maiores valores em fevereiro de 2014 com média de 4,73 UNT. Embora novembro tenha apresentado a maior precipitação, a média de turbidez foi de 0,37 UNT. Silva et al. (2008) também observaram valores de turbidez mais baixos no período chuvoso ao avaliarem a água do Rio Purus - AM. Os autores atribuíram os baixos valores de turbidez ao tamanho e natureza das partículas presentes na coluna d'água.

No presente estudo, as concentrações de OD variaram de 2,7 a 5,2 $\mathrm{mg} \mathrm{O}_{2} \mathrm{~L}^{-1}$, as quais, em sua maioria (95\%), estiveram abaixo do limite estabelecido pelo CONAMA 357/05 para um rio classe $2\left(>5,0 \mathrm{mg} \mathrm{O}_{2} \mathrm{~L}^{-1}\right.$ ). Diferentemente, os valores de DBO mantiveram-se dentro do limite $\left(<5,0 \mathrm{mg} \mathrm{O}_{2} \mathrm{~L}^{-1}\right)$, com valor máximo observado de 3,68 $\mathrm{mg} \mathrm{O}_{2} \mathrm{~L}^{-1}$.

Leandro et al. (2013), ao avaliar o mesmo trecho do RPS em agosto de 2012, encontrou valores de OD entre 5,0 e $6,4 \mathrm{mg} \mathrm{O}_{2} \mathrm{~L}^{-1}$ e obteve DBO média de $0,71 \mathrm{mg} \mathrm{O}_{2} \mathrm{~L}^{-1}$. Estes resultados evidenciam a piora da qualidade da água do rio ao longo dos anos. Os valores mais elevados de DBO observados no presente estudo podem ser atribuídos ao constante lançamento de efluentes e à redução da capacidade de diluição devido à baixa precipitação observada em agosto de 2013 e agosto de 2014, afetando diretamente a concentração de OD.

Dentre os períodos avaliados, o mês de novembro de 2013 apresentou maior DBO média $\left(2,75 \mathrm{mg} \mathrm{O}_{2} \mathrm{~L}^{-1}\right)$. Neste caso, além do lançamento de esgoto, a lixiviação de matéria orgânica causada pelas frequentes chuvas neste período pode ter contribuído para o aumento da DBO, considerando que a maioria dos pontos avaliados não possuía matas ciliares preservadas.

Os valores de DQO demonstram como os municípios envolvidos contribuem para poluição do RPS. Os menores valores de DQO foram encontrados à montante do trecho avaliado (APDM $\left.=6 \pm 3 \mathrm{mg} \mathrm{O}_{2} \mathrm{~L}^{-1}\right)$ e os maiores, à jusante $\left(\mathrm{CPTJ}_{\mathrm{J}}=12 \pm 4 \mathrm{mg} \mathrm{O}_{2} \mathrm{~L}^{-1}\right)$.

Ao longo do estudo, observou-se uma redução nos valores médios de DBO (42,4\%), ST $(31,1 \%)$ e DQO $(21,3 \%)$ quando comparados os meses de agosto de 2013 e agosto de 2014 . Esta redução pode estar associada à implantação de estações de tratamento de esgoto, no final do ano de 2013, nos municípios de Aparecida e Cachoeira Paulista, que até então não contavam com estes serviços. A implementação das ETE's pode ter contribuído para a redução destas variáveis, uma vez que efluentes, de modo geral, são particulados e ricos em matéria orgânica.

As concentrações de PT variaram de 19,4 a 40,5 $\mu \mathrm{g} \mathrm{L}^{-1}$, valores acima do limite máximo estabelecido pela Resolução CONAMA 357/05 $\left(<10 \mu \mathrm{g} \mathrm{L}^{-1}\right)$. As concentrações médias de NT mantiveram-se entre 18,1 e $27,6 \mathrm{mg} \mathrm{L}^{-1}$ em maio de 2014 e novembro de 2013, respectivamente. De acordo com Lima et al. (2016), os trechos do RPS com maior produtividade de nutrientes estão associados à maior proporção de áreas ocupadas pela agricultura e urbanização e à elevada densidade populacional. Diferentemente, a cobertura vegetal e baixa densidade demográfica resultam em trechos com baixo aporte de nutrientes. A partir dos valores anuais de PT e clorofila- $a$, calculou-se o grau de trofia do trecho avaliado, o qual foi classificado como mesotrófico, exceto pelo último ponto $\left(\mathrm{CPT}_{\mathrm{J}}\right)$, classificado como oligotrófico. Este ponto apresentava uma maior cobertura vegetal ciliar em relação aos demais pontos de coleta, o que pode ter influenciado no menor grau de trofia observado.

Como observado na Figura 1, o trecho avaliado apresenta, próximo às margens do rio, elevada taxa de urbanização e grande quantidade de áreas destinadas a lavouras e pastagens. Deste modo, o lançamento de efluentes domésticos e o arraste de nutrientes de áreas agrícolas contribuem significativamente para a produtividade de nutrientes do RPS. 
Tabela 1. Valores das variáveis físicas, químicas e biológicas de amostras de água do Rio Paraíba do Sul e limites estabelecidos pela Resolução CONAMA 357/05 para um corpo hídrico Classe 2.

\begin{tabular}{|c|c|c|c|c|c|c|c|c|c|c|c|c|c|}
\hline & Pontos & $\mathrm{pH}$ & $\begin{array}{c}\text { Temper. } \\
{ }^{\circ} \mathrm{C}\end{array}$ & $\begin{array}{c}\mathrm{CE} \\
\mu \mathrm{S} . \mathrm{cm}^{-1} \\
\end{array}$ & $\begin{array}{c}\text { Turbidez } \\
\text { UNT }\end{array}$ & $\begin{array}{c}\mathrm{OD} \\
\mathrm{mg} . \mathrm{L}^{-1}\end{array}$ & $\begin{array}{l}\text { DBO } \\
\text { mg.L } L^{-1}\end{array}$ & $\begin{array}{l}\text { DQO } \\
\text { mg.L-1 }\end{array}$ & $\begin{array}{c}\text { PT } \\
\mu \mathrm{g} . \mathrm{L}^{-1}\end{array}$ & $\begin{array}{c}\mathrm{NT} \\
\mathrm{mg} \cdot \mathrm{L}^{-1}\end{array}$ & $\begin{array}{l}\text { Clo- } a \\
\mu \mathrm{g} . \mathrm{L}^{-1} \\
\end{array}$ & $\begin{array}{c}\mathrm{ST} \\
\mathrm{mg} \cdot \mathrm{L}^{-1}\end{array}$ & $\begin{array}{c}\mathrm{CT} \\
\text { NMP. } 100 \mathrm{~mL}^{-1}\end{array}$ \\
\hline \multirow{8}{*}{ 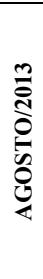 } & $\mathrm{APD}_{\mathrm{M}}$ & 6,2 & 21,6 & 90 & 0,53 & 4,63 & 1,88 & 2,81 & 27,1 & 22,5 & 1,58 & 104,0 & $2,810^{3}$ \\
\hline & $\mathrm{APD}_{\mathrm{J}}$ & 6,2 & 22,7 & 90 & 0,23 & 4,45 & 3,68 & 4,24 & 31,2 & 23,5 & 0,45 & 142,7 & $>1,610^{5}$ \\
\hline & GUAM $_{M}$ & 6,2 & 22,4 & 80 & 0,10 & 4,15 & 3,08 & 11,14 & 28,8 & 22,5 & 0,42 & 115,0 & $5,410^{4}$ \\
\hline & GUA $_{J}$ & 6,3 & 22,7 & 90 & 0,22 & 4,23 & 3,28 & 18,76 & 28,6 & 29,0 & 1,08 & 125,0 & $1,710^{4}$ \\
\hline & $\mathrm{LOR}_{\mathrm{M}}$ & 6,6 & 23,9 & 170 & 0,10 & 4,67 & 3,16 & 14,24 & 25,0 & 32,0 & 1,86 & 121,0 & $4,610^{3}$ \\
\hline & $\mathrm{LOR}_{\mathrm{J}}$ & 6,6 & 22,4 & 100 & 0,09 & 4,25 & 1,78 & 13,05 & 25,8 & 31,0 & 0,69 & 141,0 & $5,410^{4}$ \\
\hline & $\mathrm{CPT}_{\mathrm{M}}$ & 6,4 & 21,6 & 90 & 0,27 & 3,93 & 2,14 & 13,05 & 41,6 & 26,0 & 3,00 & 120,3 & $1,710^{3}$ \\
\hline & $\mathrm{CPT}_{\mathrm{J}}$ & 6,5 & 21,7 & 90 & 0,12 & 4,37 & 1,37 & 14,95 & 29,1 & 18,5 & 1,12 & 114,3 & $3,310^{3}$ \\
\hline \multirow{8}{*}{ 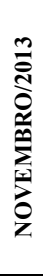 } & $\mathrm{APD}_{\mathrm{M}}$ & 6,6 & 24,0 & 90 & 0,11 & 4,20 & 2,25 & 2,65 & 29,0 & 23,0 & 5,29 & 221,0 & ND \\
\hline & $\mathrm{APD}_{\mathrm{J}}$ & 6,5 & 24,0 & 90 & 0,19 & 3,90 & 3,67 & 9,48 & 31,9 & 24,5 & 5,27 & 115,3 & $2,810^{3}$ \\
\hline & $\mathrm{GUA}_{\mathrm{M}}$ & 6,6 & 23,8 & 80 & 0,14 & 4,20 & 3,62 & 12,81 & 26,2 & 32,0 & 6,38 & 106,7 & ND \\
\hline & GUAJ & 6,4 & 23,9 & 80 & 0,54 & 4,23 & 2,89 & 4,24 & 26,4 & 38,5 & 7,57 & 208,7 & $4,910^{3}$ \\
\hline & $\mathrm{LOR}_{\mathrm{M}}$ & 6,7 & 24,3 & 90 & 0,21 & 4,23 & 3,67 & 15,03 & 28,4 & 41,5 & 7,76 & 128,7 & $3,510^{2}$ \\
\hline & $\mathrm{LOR}_{\mathrm{J}}$ & 6,2 & 23,7 & 70 & 0,23 & 4,20 & 1,85 & 13,44 & 29,1 & 26,0 & 6,76 & 185,3 & ND \\
\hline & $\mathrm{CPT}_{\mathrm{M}}$ & 6,8 & 24,1 & 90 & 0,58 & 3,67 & 2,13 & 21,62 & 32,4 & 18,5 & 8,25 & 143,3 & $2,810^{3}$ \\
\hline & $\mathrm{CPT}_{\mathrm{J}}$ & 6,6 & 23,9 & 240 & 0,95 & 4,35 & 1,93 & 16,46 & 30,4 & 17,0 & 5,80 & 116,0 & ND \\
\hline \multirow{8}{*}{ 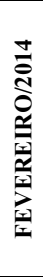 } & $\mathrm{APD}_{\mathrm{M}}$ & 6,5 & 28,4 & 100 & 3,97 & 3,87 & 1,28 & 5,83 & 25,9 & 17,0 & 1,72 & 106,7 & $7,910^{2}$ \\
\hline & $\mathrm{APD}_{\mathrm{J}}$ & 6,2 & 27,9 & 70 & 4,80 & 3,15 & 2,38 & 7,57 & 23,8 & 18,0 & 2,05 & 124,3 & $>1,610^{5}$ \\
\hline & $\mathrm{GUA}_{\mathrm{M}}$ & 6,1 & 27,9 & 70 & 7,30 & 2,67 & 2,08 & 8,68 & 24,1 & 25,0 & 8,32 & 118,0 & $2,810^{3}$ \\
\hline & GUA $_{J}$ & 6,6 & 28,9 & 80 & 4,70 & 2,87 & 1,22 & 7,25 & 24,8 & 25,5 & 1,92 & 144,3 & $1,310^{4}$ \\
\hline & $\mathrm{LOR}_{\mathrm{M}}$ & 6,4 & 27,7 & 80 & 3,90 & 3,67 & 2,78 & 6,14 & 22,6 & 35,5 & 2,27 & 123,3 & $4,910^{3}$ \\
\hline & $\mathrm{LOR}_{\mathrm{J}}$ & 6,3 & 27,8 & 80 & 2,50 & 3,77 & 2,47 & 3,92 & 22,8 & 22,5 & 2,61 & 145,7 & $2,310^{3}$ \\
\hline & $\mathrm{CPT}_{\mathrm{M}}$ & 6,7 & 27,5 & 150 & 5,77 & 3,95 & 2,35 & 7,89 & 30,3 & 21,0 & 22,03 & 134,7 & $2,810^{3}$ \\
\hline & $\mathrm{CPT}_{\mathrm{J}}$ & 6,5 & 27,4 & 90 & 4,90 & 3,50 & 2,98 & 5,67 & 25,7 & 19,5 & 3,11 & 123,3 & $1,710^{3}$ \\
\hline \multirow{8}{*}{ 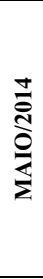 } & $\mathrm{APD}_{\mathrm{M}}$ & 6,6 & 20,9 & 70 & 2,10 & 5,20 & 0,93 & 11,62 & 20,0 & 16,0 & 0,34 & 72,0 & ND \\
\hline & $\mathrm{APD}_{\mathrm{J}}$ & 5,9 & 20,7 & 70 & 1,76 & 4,80 & 2,05 & 4,08 & 20,7 & 19,5 & 0,78 & 95,7 & $1,710^{2}$ \\
\hline & GUAM $_{M}$ & 6,2 & 21,0 & 70 & 1,92 & 4,40 & 1,57 & 10,27 & 20,4 & 26,5 & 0,58 & 74,3 & $9,210^{0}$ \\
\hline & GUA $_{J}$ & 6,2 & 20,8 & 70 & 2,50 & 4,70 & 1,75 & 12,49 & 24,1 & 28,5 & 1,37 & 100,0 & $4,610^{2}$ \\
\hline & $\mathrm{LOR}_{\mathrm{M}}$ & 6,8 & 21,1 & 80 & 2,40 & 4,87 & 3,27 & 19,79 & 23,4 & 32,0 & 0,34 & 99,7 & ND \\
\hline & $\mathrm{LOR}_{\mathrm{J}}$ & 5,9 & 20,8 & 70 & 1,67 & 4,75 & 0,88 & 13,29 & 23,6 & 11,0 & 0,23 & 87,7 & ND \\
\hline & $\mathrm{CPT}_{\mathrm{M}}$ & 6,1 & 21,5 & 80 & 2,30 & 4,45 & 1,34 & 12,02 & 23,0 & 7,0 & 0,18 & 87,7 & ND \\
\hline & $\mathrm{CPT}_{\mathrm{J}}$ & 6,0 & 21,1 & 80 & 1,59 & 5,00 & 2,20 & 13,76 & 24,5 & 4,5 & 0,28 & 114,7 & ND \\
\hline \multirow{8}{*}{ 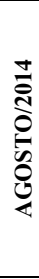 } & $\mathrm{APDM}_{\mathrm{M}}$ & 6,0 & 20,2 & 80 & 0,59 & 4,50 & 1,20 & 6,14 & 46,5 & 21,0 & 3,09 & 73,0 & $1,110^{4}$ \\
\hline & $\mathrm{APD}_{\mathrm{J}}$ & 6,5 & 20,4 & 110 & 0,62 & 4,37 & 2,30 & 7,81 & 50,0 & 27,5 & 3,10 & 88,7 & $1,610^{5}$ \\
\hline & GUA $_{M}$ & 6,7 & 20,2 & 190 & 0,46 & 3,90 & 1,80 & 11,38 & 47,3 & 21,5 & 3,33 & 82,0 & $5,410^{4}$ \\
\hline & GUAJ & 6,6 & 20,5 & 90 & 0,60 & 4,23 & 0,93 & 12,97 & 46,8 & 22,5 & 2,04 & 84,0 & $9,210^{4}$ \\
\hline & $\mathrm{LOR}_{\mathrm{M}}$ & 6,2 & 20,2 & 80 & 0,45 & 4,45 & 2,28 & 9,24 & 45,5 & 37,0 & 3,67 & 83,7 & $7,910^{3}$ \\
\hline & $\mathrm{LOR}_{\mathrm{J}}$ & 6,6 & 20,4 & 80 & 0,34 & 4,57 & 1,00 & 8,21 & 46,3 & 30,0 & 3,84 & 97,7 & $1,310^{4}$ \\
\hline & $\mathrm{CPT}_{\mathrm{M}}$ & 5,9 & 20,1 & 80 & 0,43 & 3,87 & 0,76 & 9,24 & 47,6 & 29,5 & 1,42 & 83,0 & $9,210^{4}$ \\
\hline & $\mathrm{CPT}_{\mathrm{J}}$ & 6,1 & 20,1 & 80 & 0,55 & 4,60 & 1,50 & 7,57 & 47,4 & 17,5 & 0,50 & 85,3 & $3,510^{4}$ \\
\hline \multicolumn{2}{|c|}{$\begin{array}{c}\text { CONAMA } \\
357 / 05\end{array}$} & $\begin{array}{c}6<\underset{9 H}{9}< \\
9\end{array}$ & - & - & $\begin{array}{l}<40 \\
\text { UNT }\end{array}$ & $\begin{array}{l}>5,00 \\
\operatorname{mg~L}^{-1}\end{array}$ & $\begin{array}{l}<5,00 \\
\operatorname{mg~L^{-1}}\end{array}$ & - & $\begin{array}{c}<10 \\
\mu \mathrm{g} \mathrm{L} L^{-1}\end{array}$ & - & $\begin{array}{c}<30 \\
\mu \mathrm{g} \mathrm{L^{-1 }}\end{array}$ & - & $\begin{array}{c}1000 \\
\text { NMP } \\
100 \mathrm{~mL}^{-1}\end{array}$ \\
\hline
\end{tabular}

O limite de CT estabelecido pela Resolução CONAMA 357/05 (1000 NMP.100 mL ${ }^{-1}$ ) foi excedido em $83 \%$ das amostras, o que demonstra forte lançamento de efluentes domésticos sem tratamento adequado. Vasconcellos et al. (2006), ao determinarem a presença de CT nas águas do Rio São Lourenço-RS, obtiveram $80 \%$ das amostras com valores acima do estabelecido, permitindo que os autores classificassem estas águas como impróprias para o consumo humano. Além disso, valores tão elevados podem tornar o tratamento desta água caro, devido a necessidade de etapas adicionais para total remoção destes micro-organismos. De acordo com ANA (2012), os municípios paulistas de Taubaté e Aparecida apresentam os maiores valores de CT do RPS. Valores elevados podem ser relacionados à poluição por efluentes domésticos sem tratamento adequado. Em alguns pontos do trecho avaliado foi observado este tipo de fonte poluidora de forma pontual. O ponto APDJ, localizado próximo a uma dessas fontes pontuais, mostrou-se positivo para a presença de CT durante todo o estudo, apresentando concentrações muito elevadas. Estes resultados reforçam a importância da implantação de ETE's no Rio Paraíba do Sul para garantia da qualidade da água para o abastecimento público. 


\subsection{Efeito tóxico agudo e crônico}

Do total de 40 amostras avaliadas neste estudo, 22,5\% apresentaram ETC utilizando a alga $R$. subcapitata e 5\% apresentaram ETA agudo para D. similis. O mês de novembro de 2013 apresentou ETA e ETC, diferente do mês de fevereiro de 2014, no qual foi observado apenas ETC (Tabela 2).

Tabela 2. Resultados dos bioensaios para determinação de efeito tóxico agudo (ETA) com $D$. similis e efeito tóxico crônico (ETC) com $R$. subcapitata a partir das amostras de água do Rio Paraíba do Sul, coletadas trimestralmente durante o período de agosto de 2013 e agosto de 2014.

\begin{tabular}{|c|c|c|c|c|c|c|c|c|c|c|}
\hline & \multicolumn{2}{|c|}{ Ago/13 } & \multicolumn{2}{|c|}{ Nov/13 } & \multicolumn{2}{|c|}{$\mathrm{Fev} / 14$} & \multicolumn{2}{|c|}{ Mai/14 } & \multicolumn{2}{|c|}{ Ago/14 } \\
\hline Pontos & ETA & ETC & ETA & ETC & ETA & ETC & ETA & ETC & ETA & ETC \\
\hline $\mathrm{APD}_{\mathrm{M}}$ & - & - & TOX & - & - & TOX & - & - & - & - \\
\hline $\mathrm{APD}_{\mathrm{J}}$ & - & - & - & TOX & - & - & - & - & - & - \\
\hline $\mathrm{GUA}_{\mathrm{M}}$ & - & - & TOX & TOX & - & - & - & - & - & - \\
\hline $\mathrm{GUA}_{J}$ & - & - & - & - & - & TOX & - & - & - & - \\
\hline $\mathrm{LOR}_{\mathrm{M}}$ & - & - & - & - & - & TOX & - & - & - & - \\
\hline $\mathrm{LOR}_{\mathrm{J}}$ & - & - & - & TOX & - & - & - & - & - & - \\
\hline $\mathrm{CPT}_{\mathrm{M}}$ & - & - & - & TOX & - & TOX & - & - & - & - \\
\hline $\mathrm{CPT}_{\mathrm{J}}$ & - & - & - & - & - & TOX & - & - & - & - \\
\hline
\end{tabular}

Nota: TOX: Efeito Tóxico Observado.

Bioensaios realizados a partir de amostras de água do RPS, utilizando Ceriodaphnia dubia, no ano de 2013, não apresentaram ETA. Porém, em 16\% das amostras foi detectado ETC (CETESB, 2009).

Em estudos de fitotoxicidade com Allium cepa realizados nos municípios de Tremembé e Aparecida nos anos de 2005 e 2006, as amostras de água do RPS promoveram o decréscimo no comprimento das raízes e a redução do índice mitótico (Barbério et al., 2009). Em testes de genotoxicidade utilizando $A$. серa para avaliar a água coletada no município de Tremembé em 2008, foram observadas anomalias cromossômicas nas células tratadas com a água coletada no período chuvoso (Oliveira et al., 2011).

No presente estudo, o efeito tóxico foi observado somente no período de maior precipitação. A maioria dos pontos analisados não possui matas ciliares às margens do RPS, e em alguns casos apresentam regiões impermeáveis. Solos sem cobertura vegetal estão sujeitos ao deslocamento de poluentes tóxicos para os rios por meio da lixiviação. Neste caso, a presença de vegetação próxima às margens do rio oferece proteção contra estes contaminantes (Coelho-Souza et al., 2007; Randhir et al., 2013). A degradação da vegetação promovida pela urbanização e atividades agrícolas pode ter favorecido o deslocamento de compostos tóxicos para o rio durante o período chuvoso, resultando no efeito tóxico observado.

\subsection{Análises estatísticas}

A partir da análise de Correlação de Spearman foi observada correlação negativa significativa $(p<0,05)$ entre a precipitação e o OD $(-0,402)$. Por outro lado, correlações positivas significativas $(\mathrm{p}<0,05)$ foram observadas entre a precipitação e temperatura $(0,570)$, ETC $(0,550)$, ETA $(0,324)$, ST $(0,394)$ e clorofila-a $(0,562)$. Os resultados apresentados reforçam a relação entre índice pluviométrico, erosão e consequente lixiviação de compostos tóxicos e matéria orgânica para o rio. Estes eventos podem ser observados a partir da redução 
de OD, pelo aumento de ST e pelo ETA e ETC observado nos períodos de maior precipitação.

Os períodos de coleta foram avaliados utilizando a ACP. A variância acumulada foi explicada em $66,53 \%$, sendo que o primeiro componente contribuiu com $28,9 \%$, o segundo com $15,9 \%$, o terceiro com $11,6 \%$ e o quarto com $10,1 \%$. O número de componentes foi determinado pela regra de Kaiser, na qual o último componente significativo dever ser aquele cujo autovalor é igual ou superior à média dos demais autovalores.

Os parâmetros temperatura $(0,873)$, precipitação $(0,746)$, ETC $(0,716)$, clorofila- $a(0,663)$ e ST $(0,661)$ apresentaram os maiores valores de correlação no componente 1 , que apresentou maior variância explicada $(28,99 \%)$. Em oposição, o menor valor corresponde ao OD $(-0,669)$. Neste caso, também é possível relacionar o período chuvoso (novembro de 2013 e fevereiro de 2014) ao arraste de compostos tóxicos e matéria orgânica para o corpo hídrico, resultando no efeito tóxico observado e na redução da solubilidade do OD.

Pela análise dos demais componentes selecionados, os parâmetros mais significativos foram DQO $(0,616)$, PT $(0,581)$, NT $(0,462), \mathrm{pH}(0,556)$ e condutividade $(0,509)$. Deste modo, é possível associar estas variáveis à poluição causada pelo lançamento de efluentes domésticos e industriais. Este tipo de impacto é muito comum sobre os rios da bacia do RPS, uma vez que a região é altamente industrializada e apresenta elevada densidade populacional.

Observou-se no gráfico da ACP um distanciamento entre os períodos com elevada precipitação (novembro de 2013 e fevereiro de 2014) e os demais períodos (Figura 3). Este distanciamento se deve às diferentes características conferidas ao rio pela ação das chuvas.

A distribuição espacial e temporal das chuvas é um fator que influencia fortemente os aspectos físicos, biológicos e socioeconômicos da região da bacia do RPS (Alvarenga et al., 2012). A chuva é um evento que altera as características de um corpo hídrico, bem como do ambiente ao seu redor. As variações pluviométricas ao longo do ano geram diferentes tipos de padrões sazonais que alteram a intensidade dos processos ambientais. Processos erosivos são desencadeados levando à lixiviação de matéria orgânica, nutrientes e poluentes. Além disso, as chuvas modificam o regime de vazão de corpos hídricos, aumentando a capacidade de diluição destes compostos (Santos et al., 2010; Geraldes e George, 2012). Neste contexto, observa-se que o período chuvoso surge como um agente intensificador dos impactos causados no RPS.

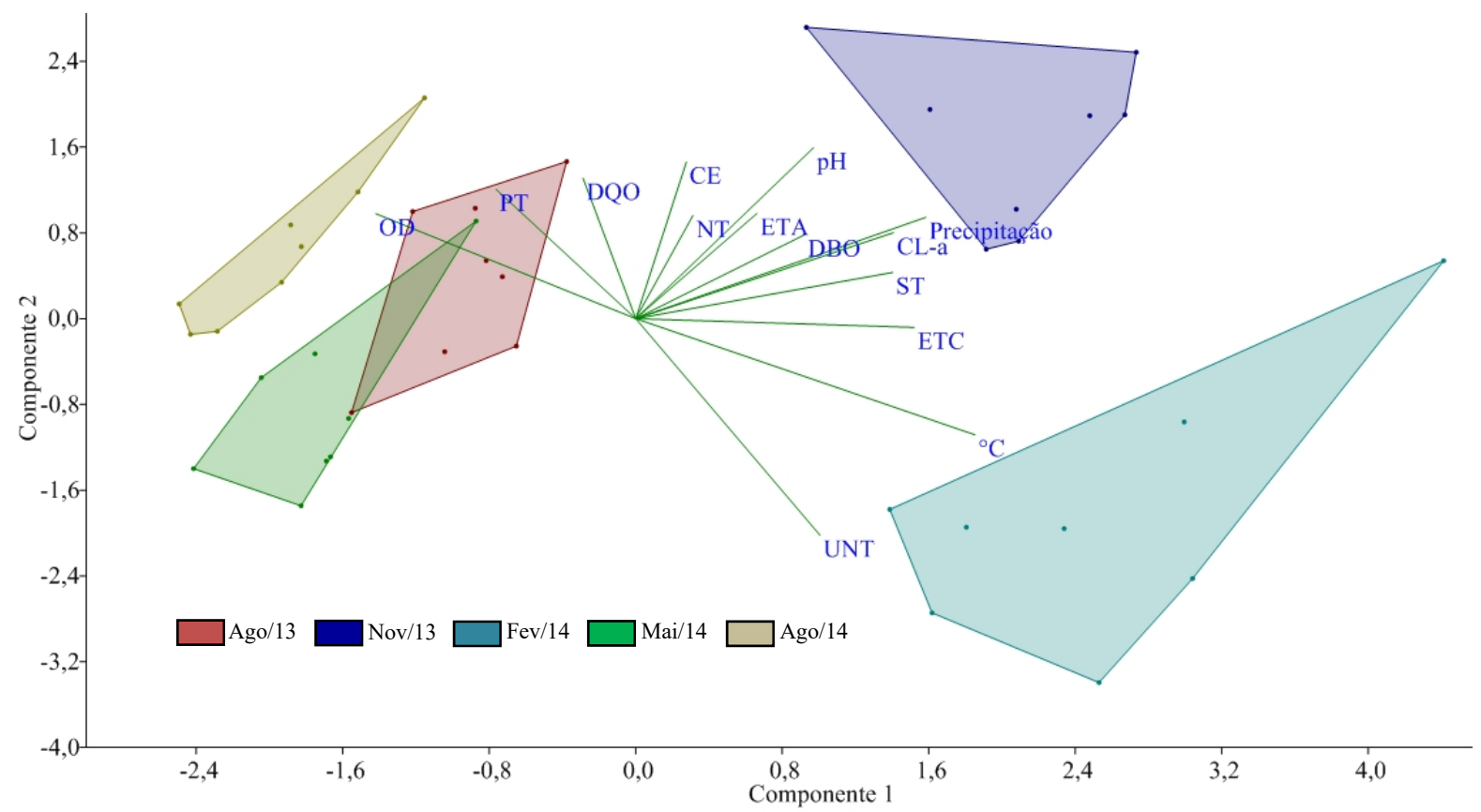

Figura 3. Análise dos Componentes Principais (ACP) das variáveis físicas, químicas e ecotoxicológicas do Rio Paraíba do Sul, em diferentes períodos do ano. 


\section{CONCLUSÕES}

Os baixos níveis de OD, as elevadas concentrações de PT e a presença de CT evidenciaram os impactos causados pelo lançamento de esgotos domésticos sobre o Rio Paraíba do Sul e demonstraram a necessidade de se investir em ações para adequar a qualidade da água deste manancial às exigências estabelecidas pela Resolução CONAMA 357/05. Dentre as ações, destacam-se a implantação de ETE's, a proteção da cobertura vegetal ciliar e o planejamento sobre a ocupação do solo na bacia.

A ocorrência de ETA e ETC somente no período chuvoso demonstrou que a chuva promoveu o arraste de compostos tóxicos para a coluna d'água, podendo causar prejuízos à biota aquática. Outras variáveis também se mostraram influenciadas pelas chuvas, como a DBO, clorofila- $a$ e os ST que apresentaram correlação positiva com o aumento da precipitação, e o OD que obteve correlação negativa. Deste modo, os resultados obtidos neste trabalho demonstraram que as chuvas, além de alterar as características da água do Rio Paraíba do Sul, atuam como um agente intensificador de impactos.

\section{AGRADECIMENTOS}

À CAPES e ao FEHIDRO pelo apoio e suporte a esta pesquisa.

\section{REFERÊNCIAS}

AlvarengA, L. A.; MARTINS, M. P. P.; CUARTAS, L. A.; PENTEAdO, V. A.; ANDRADE, A. Estudo da qualidade e quantidade da água em microbacia, afluente do Rio Paraíba do Sul - São Paulo, após ações de preservação ambiental. Revista Ambiente \& Água, v. 7, n. 3, p. 228-240, 2012. http:/dx.doi.org/10.4136/ambi-agua.987

AGÊNCIA NACIONAL DE ÁGUAS - ANA (Brasil). Panorama da qualidade das águas superficiais do Brasil. Brasília, 2012.

AMERICAN PUBLIC HEALTH ASSOCIATION - APHA; AMERICAN WATER WORKS ASSOCIATION - AWWA; WATER POLLUTION CONTROL FEDERATION - WEF. Standard methods for the examination of water and wastewater analysis. $21 \mathrm{st}$ ed. Washington, 2005.

ASSOCIAÇÃO BRASILEIRAS DE NORMAS TÉCNICAS - ABNT. NBR 9898. Preservação e técnicas de amostragem de efluentes líquidos e corpos receptores. Rio de Janeiro, 1987.

ASSOCIAÇÃO BRASILEIRAS DE NORMAS TÉCNICAS - ABNT. NBR 12648. Ecotoxicologia aquática - Toxicidade crônica - Método com algas (Chlorophyceae). Rio de Janeiro, 2011.

ASSOCIAÇÃO BRASILEIRAS DE NORMAS TÉCNICAS - ABNT. NBR 12713. Ecotoxicologia aquática - Toxicidade aguda - Método de ensaio com Daphnia spp (Crustacea, Cladocera). Rio de Janeiro, 2016.

BARBÉRIO, A.; BARROS, L.; VOLTOLINI, J. C.; MELLO, M. L. S. Evaluation of the cytotoxic and genotoxic potencial of water from the River Paraíba do Sul, in Brazil, with the Allium cepa L. test. Brazilian Journal of Biology, v. 69, n. 3, p. 837-842, 2009. http://dx.doi.org/10.1590/S1519-69842009000400010 
CARVALHO, K. Q.; LIMA, S. B.; PASSIG, F. H.; GUSMÃO, L. K. SOUZA, D. C.; KREUTZ, C.; BELINI, A. D.; ARANTES, E. J. Influence of urban área on the water quality of the Campo River basin, Paraná State, Brazil. Brazilian Journal of Biology, v. 75, n. 4, p. 96-106, 2015. http://dx.doi.org/10.1590/1519-6984.00413suppl

COMITÊ DE INTEGRAÇÃO DA BACIA HIDROGRÁFICA DO RIO PARAÍBA DO SUL CEIVAP. Dados Geoambientais. Disponível em:

http://www.ceivap.org.br/geoambientais.php.Acessoem:20março2014

COELHO-SOUZA, S. A.; MIRANDA, M. R.; GUIMARÃES, J. R. D. The importance of aquatic macrophytes in mercury cycle in Tapajós river (PA). Oecologia Australis, v. 11, n. $2,2007$.

COMPANHIA DE TECNOLOGIA E SANEAMENTO AMBIENTAL - CETESB. Significado ambiental e sanitário das variáveis de qualidade das águas e dos sedimentos e metodologias analíticas e de amostragem. São Paulo, 2009.

CONSELHO NACIONAL DO MEIO AMBIENTE - CONAMA (Brasil). Resolução n³57, de 17 de março de 2005. Diário Oficial [da] União, Brasília, 2005.

DEMANBORO, A. C. Gestão ambiental e sustentabilidade na macrometrópole paulista - Bacia do Rio Paraíba do Sul. Sociedade e Natureza, v. 27, n. 3, p. 515-530, 2015.

GALVANI, F.; GAERTNER, E. Adequação da metodologia Kjeldahl para determinação de nitrogênio total e proteína bruta. Brasília: EMBRAPA, 2006.

GERALDES, A. M.; GEORGE, C. Limnological variations of a deep reservoir in periods with distinct rainfall patterns. Acta Limnologica Brasiliensis, v. 24, n. 4, p. 417-426, 2012.

LORENZEN, C. J. Determination of chlorophyll and pheopigments: spectrophotometric equations. Limnology and Oceonography, v. 12, p. 343-346, 1967. http://dx.doi.org/10.4319/lo.1967.12.2.0343

MARENGO, J. A.; ALVES, L. M. Tendências hidrológicas da Bacia do Rio Paraíba do Sul. Revista Brasileira de Meteorologia, v. 20, n. 2, p. 215-226, 2005.

MALAFAIA, J. P.; MIRANDA, A. C.; GOMES, H. P. A Bacia do Rio Paraíba do Sul: cenário de uma atividade de EA a partir de problemas ambientais. ANAP Brasil, v. 5, n. 5, p. 112, 2012. http://dx.doi.org/10.17271/19843240552012394

OLIVEIRA, L. M.; VOLTOLINI, J. C.; BARBÉRIO, A. Potencial mutagênico dos poluentes na água do Rio Paraíba do Sul em Tremembé, SP, Brasil, utilizando o teste Allium cepa. Revista Ambiente \& Água, v. 6, n. 1, 2011. http://dx.doi.org/10.4136/ambi-agua.176

PASSIG, F. H.; LIMA, S. B.; CARVALHO, K. Q.; HALMEMAN, M. C. R.; SOUZA, P. C.; GUSMÃO, L. K. Monitoring of urban and rural basins: water quality of Mourão basin. Brazilian Journal of Biology, v. 75, n. 4, p. 158-164, 2015. http://dx.doi.org/10.1590/1519-6984.01213suppl

RANDHIR, T. O.; EKNESS, P. Water quality change and habitat potential in riparian ecosystems. Ecohydrology \& Hidrobiology, v. 13, p. 192-200, 2013. http://dx.doi.org/10.1016/j.ecohyd.2013.09.001

SANTOS, G. G.; GRIEBELER, N. P.; OLIVEIRA, L. F. C. Chuvas intensas relacionadas à erosão hídrica. Revista Brasileira de Engenharia Agrícola e Ambiental, v. 14, n. 2, p. 115-123, 2010. http://dx.doi.org/10.1590/S1415-43662010000200001 
SILVA, A. E. P.; ANGELIS, C. F.; MACHADO, L. A. T.; WAICHAMAN, A. V. Influência da precipitação na qualidade da água do Rio Purus. Acta Amazonica, v. 38, n. 4, p. 733 742, 2008. http://dx.doi.org/10.1590/S0044-59672008000400017 